\title{
Erratum: Why cannot the term development just be dropped altogether? Some reflections on the concept of maturation as alternative to development discourse
}

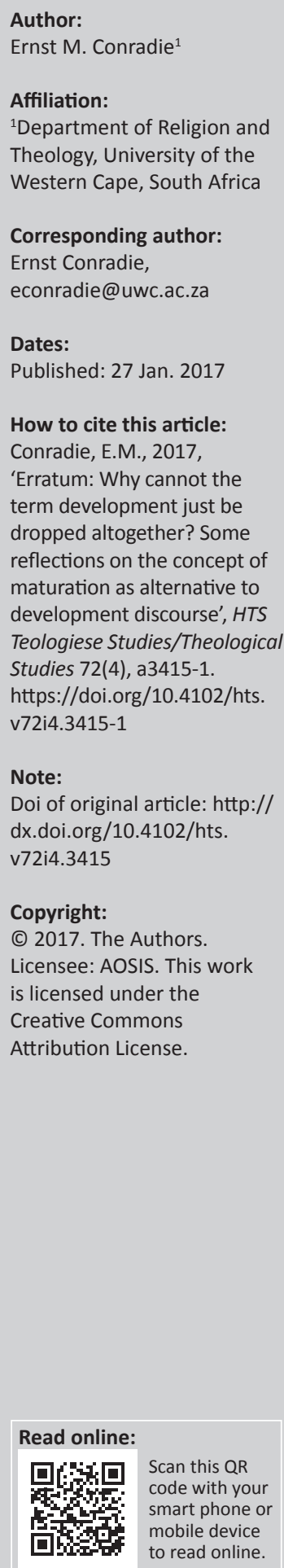

The Editor regrets that an important note was inadvertently omitted during the final editing process from the article.

The note reads: This article forms part of the special collection on 'Engaging development: Contributions to a critical theological and religious debate' in HTS Teologiese Studies/Theological Studies, Volume 72, Issue 4, 2016.

The Editor apologises. 